\title{
Economic Security as an Investment Factor of Companies Attractiveness
}

\author{
Alexandrov G.A.* \\ Department of Economics and Production Management \\ Tver State Technical University \\ Tver, Russia \\ E-mail: g-alexandrov@rambler.ru
}

\author{
Yablonev A.L. \\ Department of Technological Machines and Equipment \\ Tver State Technical University \\ Tver, Russia \\ E-mail: alvovich@mail.ru
}

\begin{abstract}
In this work the highly controversial problem of economic security is investigated as one of the essential factors determining the attractiveness of investment objects in a new aspect. At the same time, the issues of the relationship between investment attractiveness and economic security of enterprises, identification of determinants characterizing various barriers and restrictions, challenges and threats that negatively affect the situation with ensuring economic security and, as a consequence, the investment attractiveness of enterprises are considered, which finds its expression in the level of investment risks inappropriate to the interests of investors. Particular attention is paid to the methodological issues of identifying the determinants of economic security as substances of factors characterizing the investment attractiveness of enterprises, as well as evaluating these factors in the form of an unsystematic component of investment risks. The method developed in this study has a practical orientation and allows solving a two-pronged task: diagnosing the attractiveness of the invested object and evaluating investment risks, which is necessary for making a management decision on investing, and, most importantly, in the reverse order, based on the results obtained, developing and implementing specific measures both at the level of the enterprise itself, and at the sectoral, regional and country levels, eliminating all kinds of barriers, restrictions, challenges and threats, affecting the attractiveness of companies for investors.
\end{abstract}

Keywords - economic security, determinants of economic security, factors of investment attractiveness, diagnostics of investment attractiveness, assessment of unsystematic risks, threats, barriers, restrictions, challenges.

\section{INTRODUCTION}

At the current stage of development of the Russian economy, one of the most important problems is the problem of transferring it to a predominantly intensive development path, the material basis of which is the innovative renewal of the active part of fixed capital. It is clear that its solution is possible only on condition of the formation of a climate in the country favorable for doing business and creating conditions, under which motivation and incentives to invest are provided. However, with a common understanding of the importance of this problem, it still remains quite debatable and relevant in the theoretical and, as a consequence, in practical terms. At the same time, the issue of economic security became one of the debates, since it is a component of the "National Security Strategy of the Russian Federation", developed for the period up to 2030 and approved by Decree of the President of the Russian Federation No. 683 dated December 31, 2015. It formulates the goals, main directions and tasks of the State policy of the Russian Federation in the field of economic security, the implementation of which should provide resistance to challenges and threats that negatively affect economic security. At the same time, there is a growing understanding that, in turn, the state of economic security in the country is an important factor affecting the investment climate, and, above all, the investment attractiveness of enterprises, where, in fact, investment activity is carried out. And as the practice of establishing market relations shows, the "invisible hand of the market", in the figurative expression of A. Smith, which was hoped for by the proponents of liberal reforms, will automatically lead to motivation for entrepreneurs to invest and innovate. This situation is explained by the fact, that the economic environment, in which the business operates, is slowly changing in the direction of creating favorable conditions for the activities of economic entities, since there are although necessary, but far from sufficient conditions for the development of competition (recall K. Marx and his provisions on "market failure"), and this is an objective factor. It is clear that without a coherent economic policy implemented both at the enterprises themselves and in industries, regions and in the whole national economy, one cannot do. At the same time, it should be aimed at creating conditions under which enterprises could withstand all kinds of barriers and restrictions, threats and challenges objectively inherent in the market economy itself, which, by definition, is spontaneous, and also eliminate all kinds of internal negative factors and trends in activities enterprises themselves. However, the development of an adequate economic policy necessitates the solution of a number of theoretical and methodological issues in terms of, firstly, the identification and subsequent diagnosis of the most important factors, that determine the investment attractiveness of investment objects, including determinants, that determine the level of ensuring the economic security of enterprises, as well, as secondly, methods for assessing their combined impact on the investment attractiveness of enterprises. Actually, the goal of this study is to develop a methodology and offer for practical use an adequate method for it, which allows diagnosing and assessing, on the one hand, the level of economic security, as the most important component of the investment attractiveness of an enterprise, and, on the other, evaluating the latter in the form of investment risk (in this case it means its unsystematic part). 


\section{LITERATURE REVIEW AND DISCUSSION}

We do not set our task here to dwell in detail on discussions about the history of the issue and the definitions of "economic security" [1], but we will touch upon it only to clearly identify the subject of research and justify the place and role of economic security in solving the problem formulated in the introduction. First of all, we note that the appeal to this phenomenon is associated with the transition of Russia to a market economy with the objective contradictions inherent in the latter, in particular between the planned organization of production in a separate enterprise and the anarchy of production in a capitalist economy [2], which could not, but raise the problem of economic security. Meanwhile, the discussion regarding economic security is conducted in a wide and extremely opposite range. That is, from the complete denial of it, as an economic category and the assertion that, in general, the long-known phenomena and problems, that are considered through the prism of economic security, do not make sense, called these new words, especially since they really are important and urgent can be considered and resolved using existing and widely used tools, without introducing terms, to the other extreme, that is, giving economic security the role of an absolutely independent economic category and with his peculiar only to her conceptual apparatus that is causing researchers to doubt the correctness of this approach [3]. Nevertheless, this is not a reason to deny the existence of this category and, moreover, its existence at the enterprise level, as well as at the sectoral and regional levels, taking into account that they are all levels of a holistic national economic systems: enterprise - industry - region - national economy, in which they are interconnected and interdependent. Moreover, from a methodological point of view, the concept of economic security should express, on the one hand, on each of these levels the general that is inherent in this category, and, on the other, acquire specific content on each of them, due to the characteristics of each of the levels of economic hierarchy. Meanwhile, in the publications there are allegations that this category refers only to the level of the national economy [3]. Apparently, this point of view is due to the fact: in foreign literature the category of economic security is considered mainly as a State policy, that opposes threats to the country's defense capabilities and aimed at protecting people's lives [4]. Another direction in foreign studies is the problem of economic security is considered in terms of improving the quality and standard of living of the population $[5,6]$. In a number of works, this category is studied at the level of definitions, which are divided into groups, according to certain characteristic signs: economic security, as ensuring the security of all elements of the system; identification of economic security with a favorable state of the economy as a whole; economic security, as a state formed under the influence of the external environment [7]. It is easy to see, that the basis for the differentiation of definitions is based on very vague signs, which did not allow the authors to formulate a generalized clear interpretation of economic security, reveals its essence. As a result, it was reduced by the authors to such a position of the economic system of the State, in which protection against various kinds of "threats, risks and dangers is created, as well as further progressive development of the socio-economic systems of society is provided" [7]. In other words, it turned out that the category of economic security is considered only in relation to the level of the national economy, which is typical for a significant number of publications. In some, conditions are considered under which the economy is protected from various kinds of internal and external threats [8], in others, as the state of the economy, which allows defending economic and national interests, and thirdly, as resistance to negative and destabilizing factors $[9,10]$. Separately, it is worth highlighting the works that consider specific, particular factors and the determinants characterizing them, which in one way or another have an impact on ensuring economic security, such as, for example, criminalization of the economy [11], tax administration [12], rental regulation [13] etc.

Of course, various kinds of individual factors and particular aspects of economic security should be analyzed. However, at the same time, it would be, in our opinion, methodologically correct to reveal the essence of this economic category through a comprehensive analysis of the most important factors and determinants, that must be implemented, both at each, relatively independent level of the economic hierarchical system, and, that very significantly, at the level of the primary link of the national economy - an enterprise, whose economic security depends on the situation in the economic system, level and element which it is. Moreover, to conduct such an analysis, it would be appropriate to use the factor-level approach (for more details see: [1]) for analyzing the system, as a whole and separately of each of its levels, but we will discuss below the implementation of this approach. However, we note that the essence of the category "economic security" can be fully disclosed only if we can take the position of an entrepreneur, who, being the subject of assessment and already encountering certain entry barriers and limitations, challenges and threats, must evaluate all this and make an adequate management decision to create a business. Therefore, the main thing here is to diagnose the state of the environment and determine how attractive it is for entrepreneurial and, in particular, investment activities. Since the enterprise is located inside the environment, i.e. in the system of the national economy, then this environment, formed at the level of the industry, region and the national economy as a whole, affects the economic security of the enterprise, causing a certain level of external threats and challenges. However, at the same time, the enterprise itself, as an element of the system, possessing internal resistance to various threats and challenges and the ability to confront them, contributes to the formation of economic security at other levels of the national economy. Making his choice and making a decision on investing, an entrepreneur must evaluate the attractiveness of the environment, including the situation with economic security. Specifically, he must calculate the risks; evaluate the acceptable risk premium for him, being guided by his attitude (tolerance) towards him. In other words, we consider economic security as such a state of the entire economic system, in which it is resistant to all kinds of threats and challenges and, at the same time, is able to successfully counter them, overcome barriers and restrictions, and thereby ensure effective functioning and development both the economic system as a whole and its hierarchical levels. 
Thus, the economic security of the enterprise is considered, firstly, as the position of the general, that is characteristic of the economic category of "economic security" (see definition above), and, secondly, of the special, that characterizes the various primary links of the economy - the enterprise. In relation to the economic security of enterprises, threats and challenges are caused by the presence of factors and their determinants that can harm the enterprise. They are usually divided into external and internal, objective and subjective. External threats are usually caused by objective factors, the negative effects of which arise independently of enterprises and entrepreneurs. They, as noted above, are predetermined by the spontaneous nature of a market economy and its inherent contradictions and, by definition, are objective in nature. The main actors, that are potential carriers of external threats include, firstly, the State itself, which implements economic policy, develops "rules of the game" and forms a system of organizational and economic relations, and, secondly, counterparties of the enterprise, suppliers and consumers, as well as partners, and especially competitors, which are subjects of industry and inter-industry competition. As for the internal factors, that negatively affect the provision of economic security, they are largely a consequence of the ineffective activities of entrepreneurs and enterprise management, which ultimately reduces the company's ability to counter external threats and, as a result, in successful development, since it becomes not too attractive for investment. This, in fact, shows the relationship between investment attractiveness and economic security of enterprises. That is, on the one hand, problems with ensuring the economic security of the enterprise directly affect its investment attractiveness, and, on the other hand, the low level of investment attractiveness of the enterprise helps to turn potential threats into real ones, since the lack of investment does not allow business entities to maintain competitiveness at a leading level compared with competitors, and feel relatively more secure in a changing environment.

The appeal to the theoretical foundations of economic security and its relationship with investment attractiveness is small which would give in practical terms, if the solving issue of identification, differentiation, and, most importantly, the assessment of various factors and their determinants, and, accordingly, the use of for this specific methods.

\section{ASSESSMENT METHODOLOGY}

Since we consider economic security as a separate most important factor among other factors determining investment attractiveness, the factors and determinants characterizing economic security, respectively, together with other factors also affect the investment attractiveness of the hierarchical vertical, which includes levels: enterprise - industry - region country level and, which is especially important, the investment attractiveness of the enterprise, due to the situation, on the "upper floors" of the hierarchical vertical. In this regard, the solution of the issue of identification and differentiation of the totality of factors and their determinants, including those, that characterize economic security, becomes especially relevant when creating tools for diagnosing investment attractiveness and, accordingly, the unsystematic component of investment risk, the assessment of which is necessary for entrepreneurs to make an economically sound investment decision.

It should be noted that a rather large number of publications have appeared, that offer approaches and methods designed to assess the level of economic security, which are not without some drawbacks (for more details, see [1]). They consist, firstly, in that they consider the issue of determining the level of economic security, especially with regard to the enterprise, as an absolutely independent problem, but, trying to quantify this level, they are ultimately limited to qualitative characteristics, such as: low, critical, stable and so on [14]. In this regard, the question of the practical significance of such assessments cannot but arise. In addition, secondly, they cannot but raise questions about the fact, that most of the proposed methods are based on mainly expert, largely subjective estimates, which, moreover, were obtained by translating into points the results, obtained using generally accepted, widely used methods of objective analysis of the financial and economic activities of enterprises, which are then compared with their boundary values, also presented in points. At the same time, neither their economic meaning, nor their dimension, and most importantly their practical purpose, remain incomprehensible. In this regard, the question arises, but why, in fact, do the methods of objective financial and economic analysis not suit the authors, the methods they offer, when assessing the situation with ensuring economic security, moreover, the objective analysis allows identifying specific reasons that have a negative impact the company's ability to withstand external challenges and threats? Another thing is when, as noted above, economic security is considered as a factor of investment attractiveness, and in this capacity, when appraised, it turns into one of the components of the unsystematic part of the unsystematic risk presented in the discount rate, which, in turn, is an essential element in substantiation of economic feasibility of implementing investment decisions. It seems, that the causal relationships described here, may well become the basis for the development of a specific algorithm and establishes the sequence of solving a number of problems in assessing the investment attractiveness of investment objects, including assessing the level of their economic security.

According to this logic, the initial, first step in the algorithm is to identify all possible factors and their dominant characteristics, which are essentially barriers and limitations, challenges and threats, that negatively affect investment attractiveness, and then differentiate them according to which species group they relate, on the one hand, and to what hierarchical level, on the other. Thus, we present a system of "levels - groups of factors", in which specific factors will be analyzed and evaluated in close interconnection. Based on the position, that the production process in general is based on the interaction of material and personal factors, is ensured by the conditions of production (infrastructure) and certain organizational and legal relations, the formation of four main groups of factors is quite legitimate: economic, administrativelegal, resource-technical and socio-environmental. Such a factor-level approach should provide an opportunity to analyze and evaluate economic security and investment attractiveness 
so that, firstly, a potential investor, based on the diagnostic results, can make an informed investment decision; secondly, the invested entrepreneur could get a real idea of the factors and trends that negatively affect the investment attractiveness of his business; thirdly, all those, who in one way or another at their level manage the processes of forming the investment climate (including the invested entrepreneur), could decide on measures, whose implementation would help to eliminate all, that negatively affects its attractiveness.

At the second step, the assessment and selection (ranking) of the most important factors in each group and at each level are carried out, subject to further assessment, as elements of an unsystematic component of investment risk. That is, using the expert method, all identified factors are assessed using a point system, which, to one degree or another, determine investment attractiveness. The assessment is based on the opinion of several experts and can be carried out on any scale, for example, on a 5-point scale, in which 1 means low level, and 5 - accordingly high level of barriers, challenges and threats. Then it is proposed to average the expert estimates of each factor by dividing the sum of their assessments by the number of experts and calculate the Kendall concordance coefficient and, thereby, establishing the degree of consistency of expert estimates, to build the factors according to ranking from the minimum average to the maximum, that is, from factors to the minimum affecting the investment potential of the property to the maximum extent possible, which will cause low risks in the first case and high risks in the second:

$$
W=\frac{12 \sum_{I=1}^{n}\left[\sum_{j-1}^{m} y_{N}-0.5 m(n+1)\right]^{2}}{m^{2}\left(n^{3}-n\right)}
$$

where $W$ is the coefficient of concordance, which is determined in the interval $0 \leq W \leq 1$ and with full consistency is equal to one $(100 \%) ; m-$ is the number of experts; $n$ - is the number of estimated factors; $Y_{N}-$ is the sum of assessments by experts on each factor.

In other words, the level of this coefficient not lower than 70-80\% indicates a high level of expert agreement among themselves, which in turn indicates the minimization of the subjective factor and the high reliability of expert assessments. At the same time, from a large number of factors and assessments according to the rule of thumb of $\mathrm{V}$. Pareto, one can always distinguish those $20 \%$ of factors that determine the result to the greatest extent (by $80 \%$ ). That is, in this case, it is possible to distinguish in each group and at the appropriate level of factors those of them, that mainly determine the overall assessment of investment attractiveness, and subsequently the magnitude of the unsystematic component of investment risk.

At the third step, the discount rate is calculated in the part, in which it expresses the premium for unsystematic risk. We precede the consideration of this step with the intention to propose, in order to achieve greater validity of the estimates, an original approach to determining investment risk. The fact is that when using the cumulative method, scores for the unsystematic component of investment risk are determined differently in the proposed methods. Since they accept a different number of factors for assessment and use scales in which point estimates are carried out at different intervals (somewhere in the range from zero to five, in other methods from zero to ten points, or, in general, in fractions, from zero to units), as a result, the use of different methods gives different results. A relatively simple methodological technique is proposed that can provide an assessment of the unsystematic component of investment risk, regardless of the number of factors and the size of the scores. Its essence is to solve the problem of assessing unsystematic risk based on the use of not absolute, but relative values, namely, from the ratio of the unsystematic component of investment risk to its systematic component. A number of foreign studies have proved that the ratio of systematic to unsystematic risk is from 1:4 (Switzerland) to $1: 1.3$ (Netherlands) [15]. That is, the share of unsystematic risk can fluctuate over a fairly wide range, and occupy up to $80 \%$ of the total risk [16]. It follows from this that it is enough for each specific case to determine a coefficient, expressing a quantitative relationship between both parts of the total risk and multiply the values of the systematic part of the risk and the ratio to obtain the absolute value of the unsystematic component of investment risk. The coefficient itself depends on how many factors representing hierarchical levels of management received a rating that is different from zero. Based on the fact that in our "level-factor" system there are four levels and, as determined at the first step of the algorithm, four functional groups of factors, each of which contains five main factors, which more affect the assessment of investment attractiveness than the rest, then the total number of factors is eighty. Then, when evaluating all eighty factors, more than zero, the ratio of the systematic and unsystematic parts of the investment climate will be 1:4 (20\% and $80 \%$ is the maximum proportion of the unsystematic component in the overall risk). Accordingly, the more factors will have a zero score, the more the indicated ratio will change in favor of the systematic part, which will mean not only a decrease in the role of the unsystematic component of risk, but, as a consequence, a decrease in the overall risk. For example, if as a result of expert evaluations 50 factors out of 80 are estimated, the ratio of both parts will be $1: 1$ in the investment risk, and so on.

At the final fourth step of the algorithm, based on the determination at the previous step of those components of investment risk that most negatively affect investment attractiveness and identify those factors that are causing this, specific measures are developed in reverse order (at each hierarchical level), the implementation of which could ensure the elimination of the reasons for the low investment attractiveness and, as a result, ensure the reduction of risks, which naturally would have a great impact on the motivation of entrepreneurs to invest.

\section{CONCLUSION}

The article considers the problematic theoretical and methodological issues of ensuring economic security and the attractiveness of the investment climate. As a tool for diagnosing investment attractiveness and, in particular, the economic security factor for specific investment objects, as 
well as for assessing them in the form of an unsystematic component of investment risk, a number of approaches have been proposed, that provide greater reasoning and reliability of estimates, which will allow entrepreneurs to justify and accept adequate management decisions in the field of their investment activities. A certain guarantee for this is the implementation of the principles laid down in the declared approach, based on identifying the nature of the relationship between, on the one hand, the functional groups of barrier factors, challenges and threats, and, on the other hand, the levels of the economic hierarchy (enterprise - industry region - national economy). Thus, the opportunity arises: to identify them and identify the features of manifestation at various levels of the economic hierarchy; differentiate by groups of factors; assess their impact on the level of economic security and, accordingly, on the attractiveness of the investment climate; calculate the total non-systematic component of the overall risk for use as a discount rate to justify the feasibility of implementing investment decisions and, no less important, develop on this basis various kinds of practical measures aimed at eliminating those factors and trends that have a negative impact on economic safety and investment attractiveness of real investment objects. It will not be amiss to emphasize here that the use of original approaches will allow, firstly, to significantly advance in solving the problem of minimizing the role of the subjective factor, when using the method of expert assessments, and, secondly, to identify factors that characterize economic security and determine the place what they rank by rating among other factors, and as a result, and to what extent the state of economic security negatively affects the investment attractiveness of enterprises and, accordingly, on the size of investment risks.

\section{Acknowledgment}

The reported study was funded by RFBR, project number 20-010-00124.

\section{References}

[1] G.A. Aleksandrov, I.V. Vyakina, G.G. Skvortsova, "Economic Security and the Investment Attractiveness of Enterprises: the Nature of the Relationship and the Problem of Assessment”, J. of Int. Econ. Affairs, vol. 9, no. 3, pp. 2269-2284, July - September 2019. DOI: 10.18334/eo.9.3.40915.

[2] K. Marks, F. Engels, Works, 2rd ed., vol. 18. Moscow: State Publ House of Political Literat., 271 p.

[3] S.A. Afontsev, "Controversial Issues of National Economic Security Concept”, Russia XXI, vol. 2, pp. 38-67, March - April 2001.

[4] M.M. Kevin, R.H. Topel, "Some Basic Economics of National Security”, Amer. Econ. Rev., no. 103, pp. 508-511, 2013.

[5] I. Selahattin, S. Kitao, "Social Security Reforms: Benefit Claiming, Labor Force Participation, and Long-Run Sustainability", Amer. Econ. J. Macroeconomics, no. 4, pp. 96-127, 2012. DOI: 10.1257/mac.4.3.96.

[6] C.C. Courtney, Ph.B. Levine, "Recessions, Retirement and Social Security", Amer. Econ. Rev., no. 101, pp. 23-28, 2011. DOI: 10.1257/aer.101.3.23

[7] Yu.A. Salikov, V.S. Mikhailiuk, "Methodological Approach to the Terminological Analysis of the Key Concepts of Economic Security", Proc. of the Voronezh State Univer. of Engineer. Technol., vol. 81, no. 2, pp. 387-392, 2019. Retrieved from: https://doi.org/10.20914/2310-1202-2019-2-387-392

[8] A.I. Tatarkin, A.A. Kuklin, "Changing the Paradigm of Region' Economic Security Research", Econ. of the Reg., vol. 2, pp. 25-39, April - May - June 2012. DOI: 10.17059/2012-2-2.

[9] S.Yu. Glazyev, "The Foundations of Economic Security of the Country Alternative Reformation Course", Rus. Econ. J., vol. 1, pp. 3-16, 1997.

[10] A.P. Gradov, The National Economy, 2rd ed. Saint-Petersburg: Piter, $2005,240 \mathrm{p}$

[11] Yu.M. Sokolinskaya, Ye.A. Kolesnichenko, "Criminalization as a Main Threat to Economic Security", Proc. of the Voronezh State Univer. of Engineer. Technol., vol. 81, no. 1, pp. 480-484, 2019. Retrieved from: https://doi.org/10.20914/2310-1202-2019-1-480-484

[12] V.Yu. Padalkin, G.N. Strukov, A.M. Prygunkov, L.I. Churikov, "The Impact of Tax Planning on the Level of Economic Security of the Company", Proc. of the Voronezh State Univer. of Engineer. Technol. vol. 81, no. 2, pp. 383-386, 2019. Retrieved from: https://doi.org/10.20914/2310-1202-2019-2-383-386

[13] G. Alexandrov, A. Yablonev, "Score Mining Rents in Terms of Investmen Attractiveness of Peat Mining", E3S Web of Conf., vol. 21, no. 04011, November, 2017, [II-nd International Innovative Mining Symposium (Devoted to Russian Federation Year of Environment), p. 107, 2017]. Retrieved from: https://doi.org/10.1051/e3sconf/20172104011

[14] M.M. Gayfullina, Ye.V. Kostomarova, "Methodical Approach to Assessment of the Economic Safety of the Oil Company", Sci. of Sci. vol. 9, no. 2, p. 11, March - April, 2017.

[15] E.J. Elton, M.J. Gruber, Modern Portfolio Theory and Investmen Analysis, 8rd ed. New York: John Wiley\&Sons, Inc., 2009, 752 p.

[16] F.C. Evans, D.M. Bishop, Valuation for M\&A: Building Value in Private Companies, 3rd ed. New York: John Wiley\&Sons, Inc., 2009, $332 \mathrm{p}$ 